\title{
Delirar a Realidade: Por uma Escrita Antimanicomial
}

\author{
Arthur Daibert Machado Tavares* \\ Universidade do Estado do Rio de Janeiro - UERJ, Rio de Janeiro, RJ, Brasil \\ ORCID: https://orcid.org/0000-0001-6897-5187 \\ Thiago Benedito Livramento Melicio** \\ Universidade Federal do Rio de Janeiro - UFRJ, Rio de Janeiro, RJ, Brasil \\ ORCID: https://orcid.org/0000-0003-2269-1589 \\ Michelle Menezes Wendling*** \\ Universidade do Estado do Rio de Janeiro - UERJ, Rio de Janeiro, RJ, Brasil \\ ORCID: https://orcid.org/0000-0003-4165-9365 \\ Alexandra Cleopatre Tsallis $* * * *$ \\ Universidade do Estado do Rio de Janeiro - UERJ, Rio de Janeiro, RJ, Brasil \\ ORCID: https://orcid.org/0000-0002-1221-137X
}

\begin{abstract}
RESUMO
Visitando textos de Antonin Artaud, Lima Barreto, Maura Lopes Cançado e Rodrigo de Souza Leão acerca da internação psiquiátrica, este artigo aborda as relações entre corpo, escrita e política em torno da lógica manicomial e suas dissidências. Com o objetivo de propor, com os loucos, possíveis táticas de resistência ao julgamento psiquiátrico, a metodologia de pesquisa utilizada é a cartografia psicossocial, acoplada a uma análise das relações de poder. Começamos investigando as transformações históricas na separação discursiva entre razão e loucura, e de que modo elas incidiram no campo literário. Passamos, em seguida, por como o hospício cria, com a disciplina e sua prática de escrita, relações hierarquizantes e homogeneizantes que têm como efeito a individualização do corpo. Ao final, elaboramos como a linguagem poética e a criação ficcional podem funcionar, aliadas ao papel coletivo e revolucionário da literatura, como potentes estratégias antimanicomiais de resistência num convite para repensarmos nossas produções escritas.
\end{abstract}

Palavras-chave: loucura, literatura, hospício, resistência.

\section{To Rave Reality: Toward an Anti-asylum Writing}

\begin{abstract}
Visiting texts by Antonin Artaud, Lima Barreto, Maura Lopes Cançado and Rodrigo de Souza Leão about the psychiatric hospitalization, this article addresses the relationship between body, writing and politics around the logic of the asylum and its dissidences. In order to propose, with the mad, possible resistance tactics to psychiatric judgment, the research methodology used is psychosocial cartography, coupled with an analysis of power relations. We begin by investigating the historical transformation in the discursive separation between reason and madness, and how it affected the literary field. We then go through how the
\end{abstract}

ISSN $1808-4281$ 
asylum creates, with discipline and its writing practice, hierarchical and homogenizing relations that have the effect of individualizing the body. At the end, we elaborate how poetic language and fictional creation can work, combined with the collective and revolutionary role of literature, as powerful anti-asylum resistance strategies in an invitation to rethink our written productions.

Keywords: madness, literature, asylum, resistance.

\section{Delirar la Realidad: Por una Escritura Antimanicomial}

\section{RESUMEN}

Visitando textos de Antonin Artaud, Lima Barreto, Maura Lopes Cançado y Rodrigo de Souza Leão sobre la hospitalización psiquiátrica, este artículo aborda las relaciones entre cuerpo, escritura y política en torno a la lógica del asilo y sus disidencias. Para proponer, junto a los locos, posibles tácticas de resistencia al juicio psiquiátrico, la metodología de investigación utilizada es la cartografía psicosocial, junto con un análisis de las relaciones de poder. Comenzamos investigando las transformaciones históricas en la separación discursiva entre razón y locura, y cómo afectaron al campo literario. A continuación, repasamos cómo el hospicio crea, con la disciplina y su práctica de escritura, relaciones jerárquicas y homogeneizadoras que tienen el efecto de individualizar el cuerpo. Al final, elaboramos cómo el lenguaje poético y la creación de ficción pueden funcionar, combinados con el papel colectivo y revolucionario de la literatura, como potentes estrategias antimanicomiais de resistencia en una invitación a repensar nuestras producciones escritas.

Palabras clave: locura, literatura, hospicio, resistência.

Condenamos ao estrangulamento em nossos hospícios todos aqueles de quem quisemos nos livrar ou nos defender. Porque um louco é também aquele que não quisemos ouvir e a quem quisemos impedir de dizer o insuportável. É esse o problema que nos coloca Artaud (2014), no texto Van Gogh. O suicidado da sociedade. Para ele, só no delírio Vincent Van Gogh pode "encontrar uma saída para os estrangulamentos que a vida lhe prepara" (Artaud, 2014, p. 267). Suas pinturas nesse texto são bombas atômicas cujo ângulo de visão "teria sido capaz de perturbar gravemente o conformismo larvar da burguesia" (Artaud, 2014, p. 258). As pinceladas de Van Gogh recompõem a visão, "enfim lançada como nova na atualidade" (Artaud, 2014, p. 263). E é por isso que o pintor, essa terrível sensibilidade, foi considerado louco e internado: seus quadros inertes em plenas convulsões atacaram o conformismo das próprias instituições - e do próprio corpo. 
Leitor de Artaud, algumas décadas depois, Foucault (2003) propõe a seguinte questão: em sua materialidade, seu funcionamento próprio, o que verifica a validade das falas, da escrita, do discurso? Porque um louco é também aquele cujo discurso não pode circular como o dos outros, cuja palavra pode ser anulada, desconsiderada, despida de qualquer verdade ou importância. O discurso é, então, uma prática que tem sua produção organizada para conclamar seus próprios perigos e poderes. É que a palavra dos loucos, ao longo da história, foi investida de grandiosos riscos, assim como a seus corpos foram atribuídas forças sobrehumanas. Os muros dos hospícios o diriam por conta própria: na nossa cultura, entre os procedimentos de exclusão do discurso, veio se demarcar uma oposição, uma separação entre razão e loucura, afirmando ao mesmo tempo o domínio da primeira sobre a segunda. Não importa de que lado do muro estejamos. Basta que pensemos em todo o aparato de saber e poder com que deciframos os atos dos loucos, nas instituições que permitem ou convocam que falem e nas formas específicas pelas quais os escutamos: a segregação dos loucos e da loucura enquanto procedimento oficial, longe de estar apagada e desde a alta Idade Média em vigor e mutação, é ainda por nós exercida de outras maneiras, com outras consequências.

Sobre o regime de verificação ou autorização discursiva, Ribeiro (2017) nos convoca ao exercício de um olhar interseccional. É preciso, caminhando com a autora, que investiguemos não apenas como esse regime produz as dicotomias (como mente e corpo, razão e loucura), mas também os usos que as instituições fazem delas, os procedimentos pelos quais certos corpos e subjetividades têm sido silenciados e desautorizados, ao passo que outros são fortalecidos. Cabe evidenciar, nesse sentido, o caráter capacitista, branco, masculino, cis e heteronormativo da racionalidade hegemônica; mas, principalmente, a importância de uma disputa de narrativas, travada na produção de discursos e maneiras de ser contra hegemônicos, ou seja, em disfonia com a história e a ciência dominantes, articulados às inquietações e vozes que foram ativamente esquecidas, suas diferentes trajetórias e estratégias de resistência. Assim, desobedecendo à normatividade, num rompimento com o regime de autorização discursiva e seus procedimentos de segregação, precisamos utilizar de nossos espaços de poder e privilégio locais para desestabilizar as próprias hierarquias que os sustentam. Também no sentido de explicitar as condições de onde partimos, que fizeram possível a feitura deste texto, cabe situar que o presente trabalho foi realizado com apoio da Coordenação de Aperfeiçoamento de Pessoal de Nível Superior - Brasil (CAPES) - Código de Financiamento 001.

Dos girassóis inflamados ao voo dos corvos em bando, portanto, onde estão as brechas para a loucura? Como podemos aprender com os loucos - e fazer ouvir - suas forças 
giratórias, suas maneiras de rachar e furar o muro, "miná-lo e limá-lo lentamente e com paciência" (Van Gogh, 1888 como citado em Deleuze \& Guattari, 2011, p. 184)? Habitados por essas perguntas, em torno das tantas instituições que historicamente se engajaram com a loucura, nos atraem a atenção duas delas: a literatura e o hospício.

Neste texto, para nos debruçarmos sobre as relações entre elas, a metodologia de pesquisa utilizada será a cartografia psicossocial. Emprestada da geografia, como coloca Rolnik (2016), a cartografia pode ser como um desenho que acompanha e se faz ao mesmo tempo que os movimentos de mutação dos territórios existenciais, o desmanchamento e a formação de certos mundos. Para ela, seguindo as pistas da esquizoanálise de Félix Guattari e Gilles Deleuze, a tarefa do cartógrafo é estar imerso nas intensidades do campo, devorando as linguagens que lhe parecem possíveis para criar uma cartografia que dará língua aos afetos que pedem passagem. Aqui encontraremos loucos, filósofos, artistas, psiquiatras, ficcionistas, psicanalistas, poetas, sociólogos, enfim: nessa perspectiva, a cartografia é um modo de produção de pesquisa aberto às marcas dos encontros, à presença metabolizada de vozes estrangeiras que nos contagiam e se contaminam no decorrer do texto - como a análise das relações de poder, proposta por Foucault (2006), que dará vida aos embates entre corpo, disciplina e resistência. O texto então será concebido como um percurso acompanhado pela escuta de outras vozes.

Além de Antonin Artaud, nos chamam e nos encontram os testemunhos de Barreto (2010), Cançado (2015a, 2015b) e Leão (2010). Percorreremos a trilha que seus textos traçaram entre essas duas instituições - literatura e hospício - que, cada uma à sua maneira, com sua lógica, se refizeram ou mesmo nasceram a partir de uma certa concepção da desrazão e de um fazer com o corpo "ensandecido", seja pela experiência singular de criação, seja pela clausura das "ficções somatopolíticas" (Preciado, 2018) da degenerescência ou da doença mental.

\section{“Um Meio de Loucura": A Literatura Delira}

Os registros que localizam a loucura numa posição desqualificada no discurso nem sempre foram legítimos. Kiffer (2018), tomando Federici (2017) como referência, nos lembra que eles vieram historicamente tornando-se dominantes, adquirindo credibilidade ao germinarem no âmbito religioso e, com o fim da Idade Média, consolidando-se como científicos. Da inquisição a cortes seculares, hospitais gerais, hospícios e consultórios. O arco coincide com a transição econômica para um capitalismo mercantil e com a colonização do 
"novo mundo" - a nossa - empreendida pelos países europeus, podendo se estender desde a caça às bruxas e povos "selvagens" (negros, indígenas, todos aqueles possuídos por um mal a ser incendiado ou catequizado), até a internação das histéricas e dos "doentes mentais" (transtornados a serem docilizados, normalizados e transformados em lucro).

É que entre os séculos XVI e XVIII uma série de acontecimentos vem desencadear o colapso do feudalismo medieval e, ao mesmo tempo, colocar em movimento a modernidade. Nessa série, Hall (2014) ressalta o humanismo renascentista, a reforma protestante e as revoluções científicas, até chegarmos ao iluminismo cartesiano. Do lento processo nasce o chamado "sujeito do iluminismo": indivíduo soberano e consciente, a origem da razão. Em seu núcleo interior há uma identidade indivisível que permanece essencialmente idêntica. É nesse período que os dualismos entre mente e corpo, sujeito e objeto, começam a se instituir.

Entretanto, mesmo que os registros dominantes passem a exercer essa segregação, os discursos relacionados à loucura devem ser tomados como práticas descontínuas que se cruzam, ignoram ou excluem (Foucault, 2003). É assim que, aos poucos, em algum lugar, pode ser escavada uma passagem para uma experiência medicamente considerada com desconfiança: na descontinuidade do discurso, algo acontece na literatura em relação a essa posição reservada à loucura. O que ocorre é que o sistema de regulação e transformação da literatura no início do século XX era tal, que a linguagem da loucura assumiu um valor positivo e real, conquistando um lugar, podendo efetivamente funcionar como literatura até os dias de hoje (Foucault, 2016a). Para Foucault (2016b), com a linguagem da loucura, um vazio foi escavado sob as nossas palavras, despertando seus sutis imprevistos - em Artaud, uma linguagem de ausência, de um vazio fundamental. É nessa experiência mesma, ali onde as palavras falham e o pensamento desaba; na impossibilidade de falar e de pensar que a loucura, subterrânea, reencontra seu direito à linguagem na literatura.

Antonin Artaud é um dos muitos nomes desse enlace que ocorreu entre todo o sistema literário e a impossibilidade de um pensar articulado, encadeado. Seus textos não são uma plataforma de revelação de si, mas um processo em que o desenraizamento, a perda de si, é muitas vezes o único caminho para se reconfigurar. Ao mesmo tempo, diante do vazio, a escrita vem travar um combate com a experiência que pode vir a aniquilá-lo (Kiffer, 2016): capturando fragmentos, empilhando pequenos restos, ele existe literariamente, como as letras do alfabeto - escrever é uma necessidade e seu direito (Artaud, 2017). Foucault (2016b) dirá que há uma linguagem literária nos confins da loucura, e não é que toda linguagem da loucura tenha uma significação literária ou que a literatura esteja fascinada ou assombrada pela 
loucura, mas tanto uma quanto a outra jogam com os signos, têm como campo comum esses signos que jogam conosco. A literatura é um delírio, dirá Deleuze (2011).

“Então de onde vem o mal?", Artaud pergunta. É mesmo um sinal maléfico ou é "a descoberta de um mundo novo, um alargamento verdadeiro da realidade?" (Artaud, 2017, p. 38). Perante o estrangulamento da vida, o impossível que a rodeia, ao pensamento e à escrita caberia a invenção de novas possibilidades de vida, avaliando-as pela sua força de irradiação palpável, pelo critério da intensificação vital (Pelbart, 2016). Nessa direção, a literatura seria também uma saúde (Deleuze, 2011). Ao final de uma carta, Artaud nos deixa um P.S.: "Sim, eis aqui agora o único uso para o qual a linguagem ainda pode servir doravante. Um meio de loucura, de eliminação do pensamento, de ruptura, o dédalo das desrazões" (Artaud como citado em Foucault, 2016b, p. 71).

Aqui, convocamos a literatura justamente em nome dessa nova relação que estabelece com a loucura, e a loucura com ela. Por isso é valiosa a localização, feita por Derrida (2014), da literatura como uma instituição contra a instituição, encarregada de uma "democracia por vir". A literatura, em especial se pensarmos suas consequências numa vida anterior às tecnologias digitais, opera um certo desmantelamento das barreiras. Com a literatura e seu alcance, a publicação e seus ecos, Artaud podia elaborar as suas práticas de contágio. Com efeito, para Deleuze e Guattari (2014), uma literatura menor como a de Artaud tem um papel revolucionário, em que a singularidade de uma experiência é imediatamente política, em que a solidão estaria povoada da mais vivaz multiplicidade.

Mas não sem um último desvio. Foucault (2016b) alerta que à loucura é concedida a fala somente desde que tome a si mesma como tema, desde que se volte para o próprio desmoronamento de onde nasce sua escrita e se debruce sobre a própria loucura. Devemos estar atentos, portanto, se quisermos evitar uma recepção folclórica da literatura de hospício, que a maneje, muda, como objeto de entretenimento ou de conhecimento. Seria preciso pensarmos uma outra política de escrita, que leve em conta suas singularidades, mas que também possa ouvir sua heterogeneidade (Artaud, 2017), que afirme a legitimidade de sua concepção da realidade e dos atos que dela derivam (Artaud, 1979), refazendo nossos mundos no trajeto desse encontro. Portanto, essas vozes não serão ouvidas aqui apenas para falarem elas mesmas da loucura e da normalidade, mas também da arte e da ciência, do literário e do político, das relações com a diferença e de como fazer funcionar uma mutação com o corpo. 


\section{“Hospício é Deus": Escritas Manicomiais}

Recuemos alguns passos na história. Antes de ocorrer essa transformação do campo literário no século XX, quando a desqualificação do discurso enlouquecido pôde ser rachada, perfurada - mesmo que de maneira específica - nesse espaço artístico local, houve ainda alguns acontecimentos marcantes que precisam ser mencionados. Novamente na companhia de Hall (2014), poderíamos ressaltar a formação dos Estados-nação, da democracia moderna e das grandes classes no capitalismo já industrializado. O surgimento das ciências sociais e a criação da biologia darwiniana, para a qual a base da razão habita na natureza, estariam também na esteira desses acontecimentos. Se a concepção do "sujeito do iluminismo" teria reinado até o século XVIII, a partir dos novos problemas que vieram se desenhando entre os séculos XIX e começo do XX o autor localiza o nascimento de um "sujeito sociológico".

Apesar de pensar agora a formação da identidade numa relação entre o eu e a sociedade, a concepção sociológica do sujeito mantém marcado ainda o dualismo entre interior e exterior, conservando o eu nuclear. $\mathrm{O}$ indivíduo soberano permanece nos discursos da lei e da economia, da mesma forma que veremos o dualismo cartesiano se institucionalizar, finalmente, com os nascimentos da psiquiatria e da psicologia científica. As disciplinas "psi" despontam exatamente nos locais práticos de controle para uma melhor administração das pessoas, um melhor encaminhamento das anormalidades e degenerescências, incluindo as alianças eugênicas que esses objetivos possam implicar. Daí pensarmos na psiquiatria e na psicologia como híbridos entre projetos administrativos e filosóficos, herdeiras tanto da norma quanto da razão, em defesa de uma certa concepção da sociedade e da natureza humanas capaz de fortalecer o Estado-nação. Dentre as instituições possíveis de atuação desse amplo esforço de segregação, aqui percorreremos o hospício.

Se seguirmos uma breve genealogia do hospício e da psiquiatria traçada por Paulo Amarante (2007), é possível remontar ao hospital geral, em que a internação podia ser determinada por autoridades reais e judiciárias, assumindo funções diretamente políticas. Com a revolução francesa, imbuídos de um espírito de modernização, no século XIX o hospital geral foi medicalizado, tornou-se uma instituição médica, ao mesmo tempo em que a medicina ocidental foi fortemente marcada pelo hospital, hospitalizando-se. Foi nesse movimento de medicalização que os primeiros hospitais psiquiátricos, assim como a própria psiquiatria, foram fundados por Philippe Pinel. Criador também da tradição da clínica como atividade consciente e sistematicamente orientada, ditou o princípio de isolamento e um primeiro modelo terapêutico para a loucura, agora tida como questão médica passível de 
tratamento e como questão de segurança, um perigo em potencial para a sociedade. É nesse sentido que a psiquiatria e o hospício guardam entre si uma relação genética. Interessante notar que Pinel foi um dos construtores do conceito moderno de cidadania, nascente também na revolução francesa, em que a posse da liberdade é firmemente associada à posse da razão.

Assim, como coloca Artaud (1983, 1979), o homem deteve a ideia do mundo, e o fez de certa maneira que deus reaparece hoje sob aspectos científicos: as leis e costumes, a credulidade dos povos civilizados, dos especialistas, dos governantes, vieram conceder à psiquiatria o direito de medir o espírito, revesti-la de inexplicáveis luzes, jurisdição essa que exercerá segundo seus próprios padrões de entendimento. Não à toa, Bercherie (1989) diz que é preciso nos atermos ao espírito da orientação da obra de Pinel. Se, para ele, o cérebro era o núcleo da mente, a alienação mental era considerada uma desorganização cerebral. Mais da metade dos casos seriam desencadeados pelas "causas morais": paixões intensas (contrariadas ou muito duradouras) e toda sorte de excessos (costumes e hábitos irregulares, educação muito dura ou muito branda). O tratamento moral na internação consistia em aplicar "uma disciplina severa e paternal" no trato com a loucura. "Ação equilibrada" de "ameaças, recompensas e consolações" e de "grande solicitude e de uma grande firmeza" (Bercherie, 1989, pp. 41-42). "Subjugar e domar o alienado", não pela via da violência física, das correntes, de vexações, mas pela "estreita dependência de um homem que, por suas qualidades físicas e morais, seja adequado para exercer sobre ele uma influência irresistível" (Pinel como citado por Bercherie, 1989, p. 42). Tradução da loucura na linguagem da ciência psiquiátrica.

"E que encarceramento é o hospício", Artaud (1979) escreve em sua Carta aos diretores de asilos de loucos. Distante do ideal de ação equilibrada pronunciado como nãoviolência por Pinel, o hospício torna-se equiparável aos quartéis e aos cárceres, hospício “onde a brutalidade é a norma" (Artaud, 1979, p. 22-24), onde a única superioridade dos psiquiatras sobre os loucos é a força. Se até o fim do século XVIII a loucura era assinalada pelo erro, o engano, no início do século XIX o que começa a caracterizar o louco é a insurreição da força. Uma força não dominada - seja a força pura de um furioso, a força das paixões sem limites, a força que abala as ideias ou a força da intensificação indefinida de uma só ideia: é a força desencadeada que localiza, a partir da tática dos hospícios, o que é a loucura. Que pode ser a cura, então, se não a submissão dessa força? (Foucault, 2006). Os muros dos hospícios podem nos trazer a dimensão corporal, espacial, atlética, física, coreográfica e concreta do problema da força insana, que se torna ainda mais gritante, mais literal nos usos punitivos do quarto-forte (espécie de solitária) e da camisa de forças 
(tecnologia de contenção individual amplamente associada à figura do louco e hoje obsoleta diante da circulação das drogas psiquiátricas).

Partindo da questão do risco social da loucura, ou seja, da periculosidade de uma força descomunal que nesse momento passou a caracterizá-la, o tratamento manicomial vem basear-se na disciplina. A disciplina, como Foucault (2006) a concebe, é o contato entre corpo e poder, um processo de colonização do corpo que garante a fixação num certo espaço e a regulamentação das forças e dos olhares. No hospício, a disciplina se torna o modo capilar através do qual o poder psiquiátrico - "esse suplemento de poder pelo qual o real é imposto à loucura em nome de uma verdade detida de uma vez por todas por esse poder sob o nome de ciência médica, de psiquiatria" (Foucault, 2006, p. 164-165) - vem agir sobre comportamentos e hábitos daqueles que designa como loucos, para que assim possa tocar os corpos de cada um, criando um corpo de automatismos (Artaud, 1983), fazendo do corpo um território manicomial. Pensamos assim o corpo não como um simples dado de anatomia individual, mas como um terreno construído e cruzado por disputas políticas, investido por uma malha de discursos e poderes que o marcam e constituem, de forma que o próprio “indivíduo" não passa de um efeito que só pode aparecer sobre o fundo dessas redes de poder.

Reativemos o problema da relação entre a escrita e a loucura, agora não mais ao redor da literatura, mas neste novo espaço que são os corredores do hospício. É que para a disciplina exercer o controle, produzir o corpo individual, ela é constantemente levada a se utilizar da escrita. No hospício, uma certa prática de escrita é mantida pelos seus funcionários tomando como objeto a loucura, expropriando-a de suas palavras e gestos para arrancar de cada corpo uma narrativa individual. Essas anotações vêm cumprir duas funções simultâneas: a de uma horizontalização homogeneizante, pela via da nomeação, da etiquetação em classes diagnósticas e da atribuição, por exemplo, de um número para cada interno, que se vê logo na entrada despido de sua existência singular; e a de uma verticalização hierarquizante, através da vigilância piramidal e panóptica que a escrita, aliada à arquitetura, propicia. Como diz Leão (2010), na narrativa de uma internação psiquiátrica em seu livro Todos os cachorros são azuis: "Todo mundo tem um hospício por perto. ... Muita coisa pode ser um hospício" (p. 52). A escrita pode ser um hospício quando se torna uma prática manicomial de poder.

Para melhor observarmos o duplo movimento da escrita manicomial (homogeneização e hierarquização), nos leva agora pelas mãos o diário escrito por Maura Lopes Cançado durante sua segunda internação no Centro Psiquiátrico Nacional. Ela define o hospício como “mãos longas levando-nos para não sei onde - paradas bruscas, corpos sacudidos se elevando incomensuráveis: Hospício é não se sabe o quê, porque Hospício é deus" (Cançado, 2015a, p. 
26). Estava certo dia no meio de uma conversa quando um médico entrou e se pôs a ouví-la. Depois de uma risada, voltando-se para uma outra médica, ele exclama com deboche: "Esta é PP. Não há dúvida”. PP é a sigla diagnóstica para Personalidade Psicopática. É que na ficha do hospício, diz Maura, seu nome não tem valor - só serve para acrescentar mais uma psicopata para a estatística. Terminará pela vida "como essas malas, cujos viajantes visitam vários países e em cada hotel por onde passam lhes pregam uma etiqueta”. Em suas passagens pelos países da doença mental, será a mala ambulante do hospício: "PP, Paranoia, Esquizofrenia, Epilepsia, Psicose Maníaco-Depressiva, etc.” (Cançado, 2015a, p. 41).

Esse discurso classificatório e nosológico que descreve a loucura como uma série de doenças mentais, cada uma com seus elementos, é um dos modelos médicos que a psiquiatria propõe para se consolidar enquanto ciência e deslegitimar de saída a palavra da loucura (Foucault, 2006), nos dando a ver os efeitos possíveis das fichas de pacientes e dos manuais de diagnóstico e tratamento. É a mesma homogeneização existencial a que se presta o uniforme do hospício que Maura é obrigada a vestir: "Pareço ter rompido completamente com o passado, tudo começa do instante em que vesti este uniforme amorfo, ou, depois disso nada existindo - a não ser uma pausa branca e muda" (Cançado, 2015a, p. 31).

Além da uniformização, a disciplina se dá através de uma vigilância vertical e hierárquica permanente. O hospício baseia a cura (como subjugação da força) em sua organização arquitetônica particular, na maneira como nele se olha e é olhado, na maneira como tudo é registrado e codificado, que é também como se exerce o poder: "Vigiem-no, para que ele não tenha mais todas essas ideias" (Artaud, 2014, p. 271). Hospício, deus que tudo vê. E o que Foucault aposta é que a disciplina manicomial se vê obrigada a utilizar o instrumento da escrita para exercer a colonização constante do corpo dos loucos em máxima visibilidade. A arquitetura e a escrita são pensadas de uma maneira que os loucos se saibam a todo momento potencialmente vigiados, podendo sempre ser vistos - e vistos como loucos. É esse o princípio da visibilidade total e permanente: uma vigilância piramidal dos olhares que, através dos guardas e enfermeiros, vai anotando e repassando tudo que é observado sobre cada um dos que ali estão internados. Segundo a hierarquia estabelecida, esse fluxo de saber acumulado deve culminar, de baixo para cima, no próprio psiquiatra (Foucault, 2006).

Com isso, aos poucos um louco aprende também a vivenciar o julgamento daqueles que estão igualmente sob o olhar do hospício-deus, da mesma forma que aprenderá a julgar qualquer manifestação de desvio naqueles que o cercam, e a julgar de um ponto de vista psiquiátrico. "Em cada canto, olhos cor-de-rosa e frios espiam sem piscar" (Cançado, 2015a, p. 75). Nessa percepção triangular da loucura, incorporando o olhar do médico, Maura, 
Rodrigo e Lima Barreto descrevem os mais variados comportamentos, assinalam os diagnósticos que os correspondem, decidem quem é ou não é delirante, quais são os idiotas, os oligofrênicos, quais são irrecuperáveis. A não existência da insurreição depende dessa espécie de consciência psiquiátrica que os loucos devem ter daqueles que os rodeiam, para que assim a possam voltar sobre sua própria loucura, experimentando-a como doença mental (Foucault, 2006). Esse é talvez o mecanismo manicomial mais sorrateiro, o de um controle mútuo. "Estamos todos sendo monitorados" (Leão, 2010, p. 38) e o psiquiatra está em nós: não seria também assim que nos olhamos uns aos outros e a nós mesmos, ainda que estejamos do lado de fora do muro concreto? Erigimos a todo tempo manicômios mentais (Pelbart, 1990).

No diário, Maura escreve sobre o dia em que rouba o "livro de ocorrências" e arranca todas as páginas em que consta seu nome para ler mais tarde em seu quarto. Esse livro de ocorrências é onde as funcionárias do hospício vão escrevendo os acontecimentos do dia a dia. Durante a leitura, Maura conclui, com revolta, como são indiferentes e desonestas as anotações de enfermeiras, guardas e médicos, em que não aparecem suas práticas agressivas ou qualquer coisa que os possa implicar nos conflitos, comprometendo-os, como as humilhações, as ameaças e os abusos do quarto-forte (Cançado, 2015a).

Ora, tensionando a totalização da escrita de que falava Foucault, Maura nos dá a ver que o que é registrado se rege por critérios parciais, de modo que as anotações tendem a apagar alguns detalhes e ressaltar outros, utilizando-se de um vocabulário bastante específico. O que encontra no livro de ocorrências são notas cruas, secas e esparsas sobre os medicamentos aplicados, as pacientes que estiveram "alteradas" ou "calmas", alguns nomes destacados sem qualquer contextualização. São essas notas que vão compondo o olhar e a narrativa sobre cada "doente”. É esse regime gráfico específico de visibilidade do corpo que vem colaborar com a individualização psicológica dos loucos: as biografias que os prontuários e livros de ocorrências registram criam o terreno para uma extrema prontidão de reação do poder psiquiátrico que, pressupondo na individualidade um espaço interno, uma psiquê, vem intervir antes mesmo do próprio ato (Foucault, 2006). No diário, como contraponto, Maura propõe uma outra versão a essas notas. Uma narratividade em que a micropolítica manicomial ou os jogos de poder locais se veriam revelados. As partes da história omitidas pelas funcionárias, as quais Maura faz emergir para o primeiro plano, demonstram como a figura reducionista do "doente mental" é fabricada às custas de uma série de práticas e discursos manicomiais extremamente violentos (Tavares, 2020). 
No final das contas, o que é importante é que se saibam vigiadas a todo momento para que sua força seja moderada, seus riscos sejam controlados. É assim que a disciplina cria uma estreita relação entre corpo e escrita: confluindo esses dois movimentos da escrita manicomial para aquilo que podemos chamar de "julgamento divino", com Cançado (2015a), ou de “julgamento de deus”, com Artaud (1983). Na leitura de Deleuze (2011), o julgamento de deus, que é também o julgamento psiquiátrico, o julgamento do hospício-deus, "implica uma verdadeira organização dos corpos, através da qual ele age: os órgãos são juízes e julgados” (p. 168). O julgamento de deus é o que vem criar esses corpos psiquiatrizados, automatizados, etiquetados, patologizados, uniformizados e vigiados pelo aporte da escrita.

\section{“Para Acabar com o Julgamento de Deus": Escritas do Fim do Mundo}

Eu sou dado ao maravilhoso, ao fantástico, ao hipersensível; nunca, por mais que quisesse, pude ter uma concepção mecânica, rígida, do Universo e de nós mesmos. No último, no fim do homem e do mundo, há mistérios e eu creio neles. Todas as prosápias sabichonas ... sobre as certezas da ciência, me fazem sorrir e creio que este meu sorriso não é falso, nem precipitado, ele me vem de longas meditações e de alanceantes dúvidas. Cheio de mistério e cercado de mistério, talvez as alucinações que tive as pessoas conspícuas e sem tara possam atribuí-las à herança, ao álcool, a outro qualquer fator ao alcance da mão. Prefiro ir mais longe... (Barreto, 2010, pp. 64).

O trecho é de Lima Barreto, que em 1919 é internado no Hospício Nacional de Alienados pelas mãos da polícia a pedido de seu irmão. Como escreve em seu Diário do Hospício (Barreto, 2010), o irmão "tinha fé na onipotência da ciência e a crendice do hospício" (p. 47), enquanto ele próprio acreditava nos mistérios, nos enigmas. Aos poucos, podemos começar a vislumbrar uma outra política do olhar: "Imagens e sons estranhos nos instigam. Aqui há o grito que é a forma de se comunicar. Há um enigma por detrás de cada louco", escreve Leão (2010, p. 51). É então que tudo fica dourado, tudo fica azul, tudo fica verde. "Tudo ficou Van Gogh. A luz das coisas foi modificada". Rodrigo espera que, quando chegar o fim do mundo, uma "nave espacial cheia de terráqueos seja expelida no espaço sideral, levando ao menos um quadro de Van Gogh" (Leão, 2010, p. 67).

Certa vez, Rodrigo estava possuído por um espírito fértil de loucura moderna, que muitas vezes ajudou a poesia do século XX e colocou o sujeito da literatura contemporânea 
no seu devido lugar. Dizem-lhe de repente que não deve escrever sobre o hospício. Entretanto, ele escreve: "Um dia ainda sobrevivo pra mostrar todo este jogo sujo" (Leão, 2010, p. 31). Também Maura Lopes Cançado gostaria de escrever um livro sobre o hospital e como se vive ali. É que ela aposta que com o que escreve "poderia mandar aos 'que não sabem' uma mensagem" (Cançado, 2015a, p. 30-31) desse mundo sombrio. Assim, o que faz "não é, absolutamente, um diário íntimo, mas tão apenas o diário de uma hospiciada" (Cançado, 2015a, p. 132), publicado aos poucos na sessão literária do jornal em que trabalhava. Ora, como vimos, é justo quando a literatura se torna coletiva e política que encontramos nela uma aliada na resistência contra o poder psiquiátrico que habita nossos olhares. "O que sei da guerra?" - pergunta Rodrigo - “Táticas de guerrilha” (Leão, 2010, p. 66). Nessa virada de perspectiva, a escrita pode vir recrutar essas táticas de guerrilha, incorporando uma cultura poética que estremeça a racionalidade hegemônica, que mostre o jogo sujo, mande uma mensagem. Também para Artaud (2017), o dever do escritor, do poeta, é destruir o preconceito onde esteja, de sair para fora dos livros e agitar o espírito público. O que o hospício, enquanto dispositivo da terapia psiquiátrica, vampiriza e tira força, a escrita, enquanto campo de livre expressão da potência, investe e dá cores, sons e texturas.

Começamos a perceber que o próprio corpo dos "anormais" é portador de outras potências políticas. Acompanhando Preciado (2011), para além do biopoder que produz as disciplinas normativas, o corpo não deve ser considerado como um dado passivo - é ainda um espaço potente e indócil de criação que resiste aos procedimentos de produção da norma. $\mathrm{O}$ corpo, como campo de multiplicidade aberto a estranhamentos e transformações, se faz também como potência de vida no desvio das disciplinas de saber e poder sobre a anormalidade, através da rearticulação das tecnologias de produção dos corpos normais e desviantes, orgânicos e inorgânicos, humanos e não humanos - e que, ao mesmo tempo, se levanta contra esse mesmo regime de classificação e segregação.

É importante, portanto, que os loucos sejam vistos em sua agência, capazes eles mesmos de fazer delirar a norma. Para Rodrigo, "ninguém merece ser coitado" (Leão, 2010, p. 60) - está longe de pleitear um lugar no céu dos coitados e não aguenta fazer papel de vítima. Preciado (2014) insiste que a forma mais eficaz de resistência à produção disciplinar é a contraprodutividade, ou seja, a produção corporalidades e narrativas alternativas à da normalidade/anormalidade. Nesse sentido, se seguirmos as indicações de Preciado, o livro O teatro e seu duplo de Artaud (2006), bem como sua performance na emissão radiofônica intitulada Para acabar com o julgamento de deus (1983), podem ser lidos como propostas de resistência à docilização psiquiátrica, como estratégias de contradisciplina delirante. 
Desvio, rearticulação, contraprodução: o corpo se torna suscetível de "desestabilizar a trama das redundâncias dominantes" quando opera "enquanto seleção de alguns segmentos dessas mesmas cadeias de redundância" para ser capaz de "fazer unir os componentes heterogêneos de um novo edifício existencial" (Guattari, 2012, p. 32). A subversão da subjetividade é tomada, assim, como uma questão de "jogo" mais que de uma simples denúncia. Nas palavras de Maura, como um "brinquedo sério do FAZ DE CONTA" (Cançado, 2015a, p. 13). Não pretende exatamente a liberdade ou a consciência (na medida em que já se encontram impregnadas da segregação em nome da razão), mas retomar nos usos da língua o espaço da farsa, inventando subjetividades delirantes que, num embate com a subjetividade manicomial, façam desmoronar o mundo como o concebemos (Guattari \& Rolnik, 2013).

Aqui, devemos nos perguntar quais são as táticas na escrita que permitem aos loucos resistirem efetivamente a uma dominação que se pretende ela própria como absoluta - já que, de um lado, a escrita pode dar lugar às superfícies de atuação do poder, sobre as quais o corpo é rebaixado e submetido ao julgamento psiquiátrico, enquanto, por outro lado, pode chegar a um plano consistente em que se se abre à experimentação de um corpo sem órgãos - conceito criado por Deleuze e Guattari (1996) a partir de Artaud para dizer desse corpo dissidente, desfeito das formas e organizações dominantes e, assim, aberto a conexões insuspeitadas que dele se apossam ou das quais ele se apossa (Deleuze, 2011): "Saio de mim duzentas vezes ao dia e volto" (Leão, 2010, p. 68) - "Me transformo numa máquina que escreve e ela escreve o que quer que eu escreva" (Leão, 2010, p. 56).

A primeira tática de guerrilha que gostaríamos de ressaltar, pensando novamente no campo de batalha que nos abre a literatura, pode ser encontrada nas palavras de Artaud:

se voltarmos, por pouco que seja, às fontes respiratórias, plásticas, ativas da linguagem, se relacionarmos as palavras aos movimentos físicos que lhes deram origem, se o aspecto lógico e discursivo da palavra desaparecer sob seu aspecto físico e afetivo, isto é, se as palavras, em vez de serem consideradas apenas pelo que dizem gramaticalmente falando, forem ouvidas sob seu ângulo sonoro, forem percebidas como movimentos, ... a linguagem da literatura se recomporá, se tornará viva (Artaud como citado em Uno, 2012, prefácio).

Ora, esses elementos ativos da linguagem são justamente o que Artaud chamará de poesia em sua elaboração sobre o Teatro da Crueldade (que cria hibridizando diferentes 
culturas do globo e da história para combater a arte desinteressada que reinava na Europa de seu tempo). A poesia é a experiência que mobiliza o ritual, uma experimentação coletiva que capta e deriva as forças, perturba e tira os órgãos do repouso, de suas funções determinadas, tomando as formas por sua intensidade, refazendo os gestos, reinventando a respiração e seu ritmo, recriando os usos da voz. É o que permite ao corpo tornar-se aquilo que ainda não é - e o fazer nascer (Artaud, 2006). Conectando-a ao corpo sem órgãos, podemos então situar a linguagem poética como uma primeira tática de escrita antimanicomial. De acordo, Guattari (2012) toma a performance, da maneira como é concebida pela poesia contemporânea, como uma espécie de chave para atravessar o que ele chama de uma "recomposição existencial".

A segunda tática de guerrilha que se nos oferece, além da poesia, é o recurso da ficção. Para Juan José Saer, não se povoa de ficção um texto para se esquivar do rigor, mas justamente por um rigor comprometido com a complexidade - caráter complexo que um tratamento limitado ao que é cientificamente verificável implicaria numa redução, num empobrecimento. A ficção, como uma "antropologia especulativa", se emancipa das cadeias da verdade única, situando-se numa posição de fronteira entre o objetivo e o subjetivo, não podendo ser tomada como uma simples mentira. O autor dirá que, ao "dar o salto em direção ao inverificável, a ficção multiplica ao infinito as possibilidades de tratamento" (Saer, 2012, p. 3), abrindo-nos à experimentação do mundo a partir de novas perspectivas.

Já para Maurice Blanchot, renunciando à luz tranquila da linguagem usual, em relação com a dimensão de uma língua outra, na ficção "narra-se o que não se pode relatar. Narra-se o que é demasiadamente real para não arruinar as condições da realidade comedida que é a nossa" (Blanchot, 2005, p. 272) - nossa realidade comedida que só pode ser sustentada como "universal” às custas da exclusão de infinitas outras possibilidades que estão para além do eu, da consciência e da razão. A realidade fictícia funda-se no que chamamos de "irrealidade" e, entretanto, os personagens nos parecem vivos: dialogando com Blanchot, Tatiana Salem Levy dirá que é a partir do seu poder de criação numa "linguagem real, presente, que se pode viver, experimentar a ficção de maneira mais real do que se vive em muitos acontecimentos ditos 'reais"” (Levy, 2011, p. 26-27).

Pensando na urgência da produção de discursos contra-hegemônicos da qual viemos tratando, fica evidente o valor que pode ganhar a ficção para os corpos em dissonância com relação à história e à ciência que informam e organizam nossa realidade ocidental. A ficção já é uma política de reapropriação das narrativas, por exemplo, para os movimentos trans e afrofuturistas, com os quais podemos aprender para repensar os nossos usos da escrita partindo de um olhar antimanicomial: "O que é grave / é sabermos / que atrás da ordem deste 
mundo / existe uma outra // Que outra? // Não o sabemos. // O número e a ordem de suposições possíveis / neste campo / é precisamente / o infinito!” (Artaud, 1983, p. 154).

A poesia e a ficção como possíveis estratégias antimanicomiais no campo da literatura não foram escolhidas ao acaso. É que a linguagem poética de Maura, mesmo que fora dos versos, atinge sua maior potência justamente em seus contos, seus textos mais frontalmente ficcionais. Além do diário, Maura publica também esse livro de contos intitulado O sofredor do ver (Cançado, 2015b), no qual nos apresenta outros olhares sobre aqueles que, em nossa cultura manicomial, seriam vistos como apenas mais um "doente mental". É um desses contos, mais precisamente, os efeitos desse conto no hospício (efeitos narrados no diário) que dão corpo ao percurso que viemos traçando para acabar com o julgamento de deus.

O conto a que nos referimos é Introdução a Alda, escrito no hospício e publicado no Suplemento Dominical do Jornal do Brasil ainda durante a internação de Maura. No diário, ela escreve que Dona Alda era "desconhecida e só". A conheceu no pátio. "Somos indigentes nesse hospício, menina", Alda diz - ao que Maura prontamente pergunta: "Verdade? Como a senhora sabe?". Numa ironia dolorosa, ela responde: "Você não sabe? Hospital de doenças mentais. Somos indigentes e dementes" (Cançado, 2015a, p. 86). E então se cala.

"Considerado caso perdido, ninguém se lhe dirigia, levantava-se às cinco horas da manhã, ia ao pátio, onde ficava todo o dia”. Alda não mudava de posição durante horas Maura mais de uma vez sentou-se ao seu lado, levando a cada vez um bofetão no nariz. "É que ela dançaria um minueto por um toque de mão sem dor. Súbito, ela sabe, mataria o próprio medo se recebesse um beijo sem o momento que o precede", diz no conto. Alda só era abordada para ser insultada - e ela rasgava os uniformes. Era modista antes de estar internada e tinha seu próprio atelier de costura: "o fato mesmo de estar no hospício, malvestida e desprezada, devia ser um aborrecimento constante”. Alertavam que Alda era perigosa, destruía o que encontrasse. Ela não discutia e "apenas fazia o que esperavam dela: exatamente o proibido". Mas algo em Alda mudou, ou "mudaram em relação a ela as atitudes das pessoas que a cercam". Talvez possamos dizer que "Alda está caminhando para ser novamente Auda" (Cançado, 2015a, pp. 113-114).

É que apenas depois de publicar o conto no jornal, Maura descobre que é assim que se escreve seu nome: Auda. Pelo que muitos disseram, após a circulação do conto no hospício, lido e relido, sua condição ali se transfigurou. Se nos lembrarmos de Artaud, a respiração, a plástica, o afeto, o som, o movimento - a carga poética nos faz vibrar em uma pulsação comum com o texto, tornando a leitura uma etapa importante do processo. Para gerar efeitos no mundo, a poesia precisa do nosso corpo em presença, do nosso modo de existir no espaço 
que "ouve, vê, respira, abre-se aos perfumes, ao tato das coisas" (Zumthor, 2014, p. 38). Auda, Maura, os leitores e editores do jornal, loucas, guardas, enfermeiras, médicos, foram todos tomados pelo movimento comum da contra-narrativa que se criou desse encontro.

A circulação do conto reconfigurou as relações com Alda, a versão manicomial dos automatismos, de modo que abriu espaço para um novo olhar. Se escrevesse agora outro conto, Maura o chamaria de Introdução a Auda: "Porque Alda não me parece muito viva mais" - escreve - "a mulher que agora está se pintando na minha mesa caminha para outro nome. O nome que possuía antes: Auda. Acredito nisto como acredito que Auda não tenha desaparecido nunca - apenas se escondia na Alda, que usa ainda, quando necessita" (Cançado, 2015a, p. 115). É que tudo que não nasceu pode vir a nascer, diz Artaud (2006), e se a vida é assim concebida é porque é frágil, turbulenta e mutável, não podendo jamais ser eternamente fixada pelas formas: "e basta eu dizê-lo / como só eu o sei dizer / e imediatamente / verão meu corpo atual / voar em pedaços / e se juntar / sob dez mil aspectos / notórios / um novo corpo / no qual nunca mais / poderão / me esquecer" (Artaud, 1983, p. 146).

Ficção e poesia tendem justamente a inventar e agir novos mundos. Mais precisamente, não criam um outro mundo, mas nos possibilitam vivenciar o "outro do mundo" (Levy, 2011, p. 27). Quando a escrita alcança essa experiência, coloca "em xeque o presente para pensar novas maneiras de existir", pois que inventar "novos estilos de vida, novos modos de existência, são maneiras de resistir ao intolerável do presente", escapando “do aprisionamento em que o presente nos confina" (Levy, 2011, p. 137). Depois do conto, sempre que vai ao quarto de Maura, Auda deixa-lhe bilhetes com letras bonitas e firmes. Seus cabelos estão agora vermelho-fogo. Após folhear rapidamente um livro chamado Science Fiction, Auda escreve na primeira página: "Isso já estava escrito há vários anos, nas minhas partes genitais de virgem. Assinado: Maura". E em outra folha deixa ainda um último recado: "Senhorita Auda G. A., modista, não demente" (Cançado, 2015a, p 128). 


\section{Considerações Finais}

Perante os recentes e crescentes ataques à reforma psiquiátrica no Brasil, que põe em ameaça as conquistas do movimento antimanicomial, torna-se cada vez mais urgente que façamos ouvir essas vozes. Que pensemos sobre os efeitos que nossas práticas podem carregar. Que estejamos atentos à importância de reinventar nossos olhares e escritas, demolindo os manicômios mentais e compondo novos mundos e modos de existência a partir dos escombros. É o exercício a que nos convocam, cada um a seu modo, os textos de Antonin Artaud, Lima Barreto, Maura Lopes Cançado e Rodrigo de Souza Leão.

\section{Referências}

Amarante, P. (2007). Saúde mental e atenção psicossocial. Rio de Janeiro: Fiocruz.

Artaud, A. (1979). Carta aos diretores de asilos de loucos. In A. Artaud, Cartas aos poderes (pp. 21-24). Porto Alegre: Villa Martha.

Artaud, A. (1983). Para acabar com o julgamento de deus. In C. Willer (Org.), Os escritos de Antonin Artaud (pp. 145-162). Porto Alegre: L\&PM Editores.

Artaud, A. (2006). O teatro e seu duplo. São Paulo: Martins Fontes.

Artaud, A. (2014). Van Gogh: O suicidado da sociedade. In A. Artaud, Linguagem e vida (2a ed., pp. 257-290). São Paulo: Perspectiva.

Artaud, A. (2017). A perda de si: Cartas de Antonin Artaud. Rio de Janeiro: Rocco.

Barreto, L. (2010). Diário do hospício: O cemitério dos vivos. São Paulo: Cosac Naify.

Bercherie, P. (1989). Os fundamentos da clínica: História e estrutura do saber psiquiátrico. Rio de Janeiro: Zahar.

Blanchot, M. (2005). O diário íntimo e a narrativa. In M. Blanchot, O livro por vir (pp. 270278). São Paulo: Martins Fontes, 2005.

Cançado, M. L. (2015a). Hospício é deus: Diário I. Belo Horizonte: Autêntica.

Cançado, M. L. (2015b). O sofredor do ver. Belo Horizonte: Autêntica.

Deleuze, G. (2011). Crítica e clínica. São Paulo: Editora 34.

Deleuze, G., \& Guattari, F. (1996). Como criar para si um corpo sem órgãos. In G. Deleuze, \& F. Guattari, Mil platôs: Capitalismo e esquizofrenia (Vol. 3, pp. 8-27). Rio de Janeiro: Ed 34.

Deleuze, G., \& Guattari, F. (2011). O anti-Édipo: Capitalismo e esquizofrenia (Vol. 1). São Paulo: Editora 34. 
Deleuze, G., \& Guattari, F. (2014). Kafka: Por uma literatura menor. Belo Horizonte: Autêntica.

Derrida, J. (2014). Essa estranha instituição chamada literatura: Uma entrevista com Jacques Derrida. Belo Horizonte: UFMG, 2014.

Federici. S. (2017). Calibã e a bruxa: Mulheres, corpo e acumulação primitiva. São Paulo: Elefante.

Foucault, M. (2003). A ordem do discurso. São Paulo: Edições Loyola.

Foucault, M. (2006). O poder psiquiátrico. São Paulo: Martins Fontes.

Foucault, M. (2016a). O belo perigo: Conversa com Claude Bonnefoy. Belo Horizonte: Autêntica.

Foucault, M. (2016b). A linguagem da loucura. In M. Foucault, A grande estrangeira: Sobre literatura (pp. 25-72). Belo Horizonte: Autêntica.

Guattari, F. (2012). Caosmose: Um novo paradigma estético. São Paulo: Editora 34.

Guattari, F., \& Rolnik, S. (2013). Micropolítica: Cartografias do desejo. Petrópolis: Vozes.

Hall, S. (2014). A identidade cultural na pós-modernidade. Rio de Janeiro: DP\&A.

Kiffer, A. (2016). Antonin Artaud. Rio de Janeiro: EdUERJ.

Kiffer, A. (2018, Maio 11). Antonin Artaud, o exemplo anômalo. [Arquivo de vídeo]. Recuperado de https://youtu.be/oeknEid8jAU

Leão, R. S. (2010). Todos os cachorros são azuis. Rio de Janeiro: 7letras.

Levy, T. S. (2011). A experiência do fora: Blanchot, Foucault e Deleuze. Rio de Janeiro: Civilização Brasileira.

Pelbart, P. P. (1990). Manicômio Mental: A outra face da clausura. Saúde Loucura, (2), 131138.

Pelbart, P. P. (2016). O avesso do niilismo: Cartografias do esgotamento. São Paulo: n-1 edições.

Preciado, P. B. (2011). Multidões queer: Notas para uma política dos anormais. Estudos feministas, 19(1), 11-20. doi: 10.1590/S0104-026X2011000100002

Preciado, P. B. (2014). Manifesto contrassexual. São Paulo: n-1 edições.

Preciado, P. B. (2018). Testo Junkie: Sexo, drogas e biopolítica na era farmacopornográfica. São Paulo: n-1 edições.

Rolnik, S. (2016). Cartografia sentimental: Transformações contemporâneas do desejo. Porto Alegre: Sulina, UFRGS.

Ribeiro, D. (2017). O que é lugar de fala? Belo Horizonte: Letramento. 
Saer, J. J. (2012). O conceito de ficção. Revista FronteiraZ, (9), 320-325. Recuperado de https://revistas.pucsp.br/index.php/fronteiraz/article/view/12992

Tavares, A. D. M. (2020). Rachando os muros do hospício: Loucura, escrita e resistência. In A. M. Jacó-Vilela \& M. C. N. Messias (Orgs.), Clio-Psyché-Resistências: Ciência e política na história da psicologia (pp. 271-284). Curitiba: CRV.

Uno, K. A. (2012). Gênese de um corpo desconhecido. São Paulo. Editora N-1.

Zumthor, P. (2014). Performance, recepção, leitura. São Paulo: Cozac Naify.

\section{Endereço para correspondência}

\section{Arthur Daibert Machado Tavares}

Secretaria de Graduação da Psicologia

Rua São Francisco Xavier, 524, $10^{\circ}$ andar, bloco B, sala 10006, Rio de Janeiro - RJ, Brasil. CEP 20550-900

Endereço eletrônico: arthurdaibert@gmail.com

\section{Thiago Benedito Livramento Melicio}

Instituto de Psicologia - Secretaria de Graduação

Avenida Pasteur, 250, Rio de Janeiro - RJ, Brasil. CEP 22290-240

Endereço eletrônico: thiago.melicio@gmail.com

\section{Michelle Menezes Wendling}

Secretaria de Graduação da Psicologia

Rua São Francisco Xavier, 524, $10^{\circ}$ andar, bloco B, sala 10006, Rio de Janeiro - RJ, Brasil. CEP 20550-900

Endereço eletrônico: michelle_wend@ hotmail.com

\section{Alexandra Cleopatre Tsallis}

Secretaria de Graduação da Psicologia

Rua São Francisco Xavier, 524, $10^{\circ}$ andar, bloco B, sala 10006, Rio de Janeiro - RJ, Brasil. CEP 20550-900

Endereço eletrônico: atsallis@gmail.com

Recebido em: 13/06/2019

Aceito em: 04/11/2020

\section{Notas}

* Mestre e doutorando em Psicologia Social pela Universidade do Estado do Rio de Janeiro.

** Doutor em Psicologia pela Universidade Federal do Rio de Janeiro. Professor Adjunto do Departamento de Psicologia Social do Instituto de Psicologia da UFRJ.

*** Doutora em Teoria Psicanalítica pela Universidade Federal do Rio de Janeiro. Professora Adjunta do Departamento de Psicanálise da Universidade do Estado do Rio de Janeiro.

**** Professora Adjunta do Departamento de Psicologia Social e Institucional da Universidade do Estado do Rio de Janeiro. 
Arthur Daibert Machado Tavares, Thiago Benedito Livramento Melicio,

Michelle Menezes Wendling, Alexandra Cleopatre Tsallis

Financiamento: CAPES, Inova UERJ e Ministério da Saúde.

Este artigo de revista Estudos e Pesquisas em Psicologia é licenciado sob uma Licença Creative Commons Atribuição-Não Comercial 3.0 Não Adaptada. 